\title{
Growth and Metabolism of Mannitol by Strains of Saccharomyces cerevisiae
}

\author{
By DAVID E. QUAIN* AND CHRISTOPHER A. BOULTON \\ Research Laboratory, Bass PLC, 137 High Street, Burton-on-Trent, \\ Staffordshire DE14 1JZ, UK
}

(Received 2 December 1986; revised 13 February 1987)

\begin{abstract}
Of 40 polyploid strains of Saccharomyces cerevisiae screened for growth on D-mannitol $(5 \%, w / v)$, half grew well (5-20 mg dry biomass $\mathrm{ml}^{-1}$ ). Certain of these strains were unable to grow on low concentrations of mannitol $(1-2 \%, w / v)$ and others, initially unable to grow on mannitol, exhibited long-term adaptation to growth. An $\mathrm{NAD}^{+}$-dependent $\mathrm{D}$-mannitol dehydrogenase (EC 1.1.1.67) was detected in mannitol-grown yeast. Growth was dependent on mitochondrial function and was obligately aerobic. Measurement of products of metabolism and respiratory activity indicated that growth on mannitol allows catabolite derepression.
\end{abstract}

\section{INTRODUCTION}

Hitherto it has not been clear whether Saccharomyces cerevisiae can transport or even metabolize the acyclic polyol, mannitol. Evidence has suggested that mannitol is not transported into this yeast (Heredia et al., 1968; Bisson \& Fraenkel, 1983). Others have shown mannitol to be transported but not metabolized (Spoerl \& Doyle, 1968; Maxwell \& Spoerl, 1971; Canh et al., 1975). In a detailed study of the catabolism of a number of acyclic polyols by 16 yeasts, Barnett (1968) found the strain of $S$. cerevisiae tested to be incapable of growth on mannitol or other polyols. However, Tyson et al. (1979) reported doubling times and cell size of S. cerevisiae S288C grown on a wide range of carbon sources, including mannitol and another acyclic polyol, sorbitol.

Further confusion arises because mannitol dehydrogenase (D-mannitol : NAD+2-oxidoreductase, EC 1.1.1.67) has been demonstrated in brewing yeast (Muller, 1937; Wilhelmsen, 1961) and an unidentified strain of $S$. cerevisiae (Wolff \& Kaplan, 1956), neither being grown on mannitol. However, taxonomists have noted that some strains of $S$. cerevisiae can assimilate mannitol (van der Walt, 1970), although in a more recent text (Barnett et al., 1983) growth was reported either not to occur or to occur after a delay of 14-21 d. More specifically, growth of $S$. cerevisiae on mannitol has been suggested (Kirsop, 1974) or shown (Wiles, 1953; Quain, 1986) to be useful in the differentiation of brewing yeasts.

Significantly, mannitol is frequently used as an osmotic stabilizer of yeast protoplasts (Linnane \& Lukins, 1975; Cooper, 1982) and has been used to investigate the effects of increasing osmotic pressure on fermentation in S. cerevisiae (Ziffer, 1983).

In this paper we describe aspects of the physiology and biochemistry of mannitol utilization by $S$. cerevisiae. Preliminary results of this work have been reported elsewhere (Walton et al., 1984; Quain \& Boulton, 1986). Growth of $S$. cerevisiae on sorbitol is also demonstrated and briefly discussed.

\section{METHODS}

Yeast strains. The polyploid strains of $S$. cerevisiae used were obtained from the National Collection of Yeast Cultures (NCYC) at the Food Research Institute, Colney Lane, Norwich, UK, or were strains from the Bass

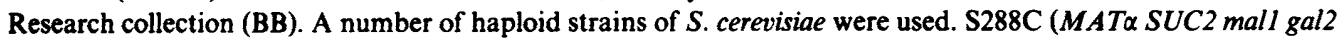
CUPl) was obtained from the Yeast Genetics Stock Center, Berkeley, Calif., USA. A184D (MAT $\alpha)$ (Woods et al., 
1974) was obtained from Dr J. M. Haslam (University of Liverpool, UK). Strains 210.1 A (MAT MAL1 SUC lysI) and 134.34C (MATa MAL6 trp ura ade) were obtained from Dr N. Eaton, Brooklyn College, NY, USA.

Growth media. Stock cultures were maintained on slopes and plates of Wallerstein Laboratories Nutrient medium (Gibco Europe).

Liquid growth medium (YEP) contained Difco yeast extract $\left(10 \mathrm{gl}^{-1}\right)$, BDH neutralized bacteriological peptone $\left(5 \mathrm{~g} \mathrm{l}^{-1}\right)$ and salts (Wallace et al., 1968) consisting of $\left(1^{-1}\right): 1.2 \mathrm{~g}^{2}\left(\mathrm{NH}_{4}\right)_{2} \mathrm{SO}_{4}, 0.5 \mathrm{~g} \mathrm{NaCl}$, $0.1 \mathrm{~g} \mathrm{CaCl}_{2} .2 \mathrm{H}_{2} \mathrm{O}, 0.7 \mathrm{~g} \mathrm{MgCl}_{2} .7 \mathrm{H}_{2} \mathrm{O}, 1 \mathrm{~g} \mathrm{KH}_{2} \mathrm{PO}_{4} .2 \mathrm{H}_{2} \mathrm{O}$ and $3 \mathrm{mg} \mathrm{FeCl}$. The medium was heat-sterilized. Sugars and ethanol were added after autoclaving.

Nitrogen starvation experiments were done in sodium phosphate buffer $(50 \mathrm{mM}, \mathrm{pH} 6)$ containing glucose $(5 \%$, $w / v)$ or mannitol $(5 \%, w / v)$.

Growth conditions. Except where noted, cultures were grown aerobically in conical flasks (nominal volume $250 \mathrm{ml}$ or 21 ) at $30^{\circ} \mathrm{C}$ on a rotary shaker at 200 r.p.m. To ensure equivalent rates of oxygen transfer, flasks were stoppered with foam bungs. Starter cultures were prepared by inoculation of a single yeast colony into $50 \mathrm{ml}$ $\mathrm{YEP} /$ glucose $(5 \%, \mathrm{w} / \mathrm{v})$ in a $250 \mathrm{ml}$ conical flask and grown with shaking for about $18 \mathrm{~h}$. Flasks were inoculated to give an initial cell concentration of $0.01-0.05 \mathrm{mg}^{\mathrm{dry}}$ weight $\mathrm{ml}^{-1}$. Strains of $S$. cerevisiae were assessed for growth on YEP/mannitol $(5 \%, \mathrm{w} / \mathrm{v})$ or YEP/sorbitol $(5 \%, \mathrm{w} / \mathrm{v})$ after incubation for $48 \mathrm{~h}$. Background growth on contaminating glucose in the medium (Fraenkel, 1982), measured for 20 strains, was $0.72 \pm 0.25 \mathrm{mg}$ dry weight $\mathrm{ml}^{-1}($ mean $\pm \mathrm{SE})$.

The involvement of oxygen in the growth of $S$. cerevisiae on mannitol was investigated by manipulating the rate of oxygen transfer to the culture and by study of aerobic-anaerobic-aerobic transitions. Rates of oxygen transfer can be manipulated by varying the culture volume (Freedman, 1969), an approach used in two experiments. Biomass yields were determined after growth in $250 \mathrm{ml}$ (actual volume $280 \mathrm{ml}$ ) conical flasks containing 15, 25, 50, 75,100 and $150 \mathrm{ml}$ culture medium. A more detailed approach involved monitoring growth in 21 (actual volume $2.4 \mathrm{l})$ conical flasks containing either 120 or $1200 \mathrm{ml} \mathrm{YEP} /$ mannitol $(10 \%)$. The effect of anaerobiosis on growth was investigated in stirred $4 \times 21$ glass fermenters containing $1200 \mathrm{ml} \mathrm{YEP} / \mathrm{mannitol}(5 \%)$ at $30^{\circ} \mathrm{C}$. Culture aeration was achieved by passing air through a sinter at a rate of $300 \mathrm{ml} \mathrm{min}^{-1}$. This was maintained until the cultures were in late exponential phase $(15 \mathrm{~h})$ when two cultures were made anaerobic by changing the gas phase to nitrogen. When the control aerobic cultures were in late stationary phase $(61 \mathrm{~h})$ the anaerobic cultures were switched back to aerobiosis.

Measurement of $N A D^{+}$-dependent mannitol dehydrogenase. Harvested and washed cells of mannitol-grown $S$. cerevisiae BB1 were suspended $(80 \%, \mathrm{w} / \mathrm{v})$ in potassium phosphate buffer $(50 \mathrm{mM}, \mathrm{pH} 7.4)$ including dithiothreitol $(1 \mathrm{mM})$ and Triton X-100 $(0.5 \% \mathrm{v} / \mathrm{v})$. Pre-cooled glass beads $(0.45-0.55 \mathrm{~mm})$ equivalent to the cell wet weight were added and the cells were disrupted at $0-4^{\circ} \mathrm{C}$ using a Braun homogenizer for $3 \times 30$ s at 4000 r.p.m. The homogenate was centrifuged at $43150 \mathrm{~g}$ for $30 \mathrm{~min}$ at $4^{\circ} \mathrm{C}$ and the resulting supernatant used for assay of enzyme activity.

Mannitol dehydrogenase activity at $30^{\circ} \mathrm{C}$ was determined spectrophotometrically by measuring the rate of increase in absorbance at $340 \mathrm{~nm}$ caused by the reduction of $\mathrm{NAD}^{+}$. The reaction mixture contained, in $1 \mathrm{ml}$ : potassium phosphate buffer $(50 \mu \mathrm{mol}, \mathrm{pH} 7 \cdot 4) ; \mathrm{NAD}^{+}(1 \mu \mathrm{mol})$; approximately $70 \mu \mathrm{g}$ cell protein; and mannitol $(75 \mu \mathrm{mol})$. Reactions were started by the addition of mannitol and the increase in $A_{340}$ was measured using a Beckman DU-7 single beam spectrophotometer with kinetics accessory. Endogenous reduction of $\mathrm{NAD}^{+}$was corrected for by initiating, in parallel, control incubations lacking mannitol. All assays were done in duplicate. Enzyme activity was shown to be proportional to protein concentration.

Other analytical procedures. Respiration was measured in a closed Clark-type electrode (Rank) at $30^{\circ} \mathrm{C}$ as described by Astin $e t$ al. (1977). Yeast dry weight was determined by drying washed $(2 \times 5 \mathrm{ml}$ deionized water) cells at $105^{\circ} \mathrm{C}$ for $48 \mathrm{~h}$. Enzymic procedures were used for the measurement of ethanol, glycerol, galactose, glucose (Boehringer Mannheim, 1980) and glycogen (Quain, 1981). Mannitol was determined using the periodate oxidation method of Lewis \& Harley (1965). Sterols were extracted after acid labilization (Gonzales \& Parks, 1977) using previously published procedures (Quain \& Haslam, 1979). Derivatized sterols were quantified using capillary gas chromatography (D. E. Quain \& R. G. Bolton, unpublished). Protein was determined by the Lowry method.

\section{RESULTS AND DISCUSSION}

\section{Screening of strains of $S$. cerevisiae for growth on mannitol}

Of the 40 polyploid strains of $S$. cerevisiae screened (Table 1), 20 were capable of good growth (5-20 mg dry wt $\mathrm{ml}^{-1}$ ) on $5 \%$ mannitol. It may therefore be concluded that the generally held view that $S$. cerevisiae cannot grow on mannitol (Barnett, 1968; Spoerl \& Doyle, 1968) nor metabolize this polyol (Maxwell \& Spoerl, 1971; Canh et al., 1975), is incorrect. Indeed we are in agreement with the taxonomists that some, but not all, strains of $S$. cerevisiae can assimilate 


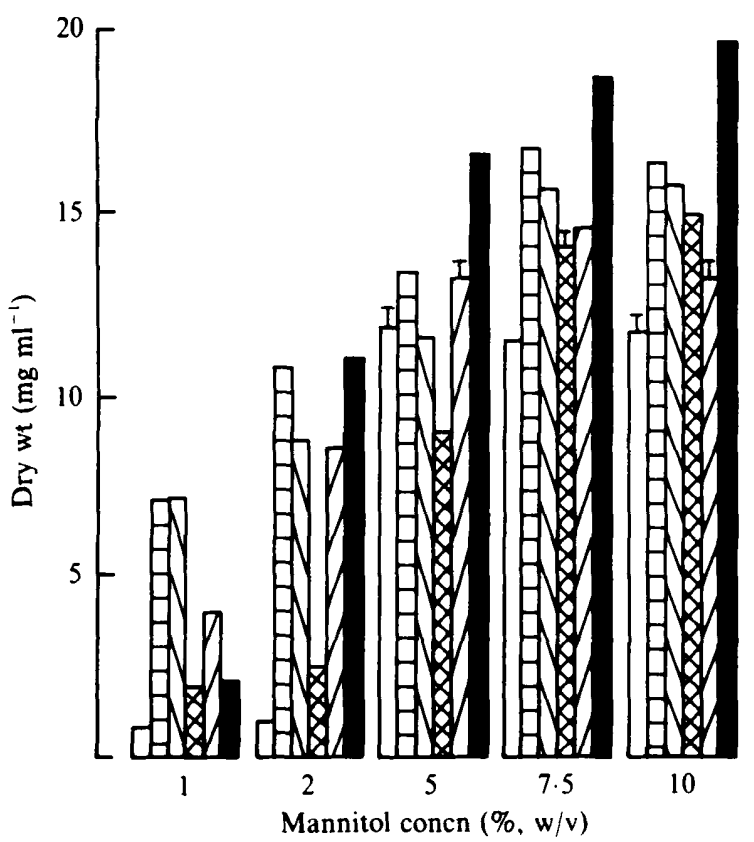

Fig. 1. Effects of mannitol concentration on yeast growth. Strains used were : BB1 ( $\square)$; BB6 (E); BB9 $(\triangle)$; BB $11(\otimes)$; NCYC $430(\square)$; and NCYC $1415(\square)$. Error bars indicate SE for two experiments; where no error bars are shown, values were identical.

Table 1. Abilities of polyploid strains of $S$. cerevisiae to grow on mannitol

$$
\begin{gathered}
\text { Poor growth } \\
\left(<2 \mathrm{mg}^{-1} \text { dry wt } \mathrm{ml}^{-1}\right)
\end{gathered}
$$

NCYC strains

BB strains
108, 202, 455, 478, 509, 684, $748,767,861,1177,1296$, $1411,1412,1413,1414$

$2,3,4,7,10$
Good growth (5-20 mg dry wt $\mathrm{ml}^{-1}$ )

$177,240,430,512,620,679$, $762,933,1048,1146,1175$,

$1176,1239,1415$

$1,5,6,8,9,11$

mannitol (van der Walt, 1970). It is unfortunate that the methods used by taxonomists for the measurement of growth are semi-quantitative so that direct comparison with the work reported here cannot be made.

Of the haploid strains of $S$. cerevisiae screened, only A184D grew on mannitol (5-10 mg dry wt $\mathrm{ml}^{-1}$ ). Contrary to previous observations (Tyson et al., 1979), S288C did not grow on mannitol $\left(<1.5 \mathrm{mg}\right.$ dry wt $\left.\mathrm{ml}^{-1}\right)$.

\section{Effect of mannitol concentration on growth}

Certain of those strains of $S$. cerevisiae exhibiting good growth on $5 \%$ mannitol were examined in more detail over a range of mannitol concentrations (Fig. 1). In general, growth yields reached a maximum at substrate concentrations of $5-7.5 \%(\mathrm{w} / \mathrm{v})$. At higher concentrations it is likely that a nutrient other than the carbon source limited growth. Of the six strains tested, three (BB1, 11 and NCYC 1415) exhibited little or no growth with $1 \%$ mannitol. With $2 \%$, NCYC 1415 grew extremely well whereas BB1 and 11 grew poorly. That all six strains grew increasingly well at mannitol concentrations of $5 \%$ and more suggests that those strains that grew poorly at low substrate concentrations had transport systems exhibiting a low affinity for mannitol, or alternatively, metabolized this substrate less efficiently. Cells of strain BBl shifted from active growth at high $(5 \%)$ concentrations of mannitol to low $(2 \%)$ concentrations, failed to grow. 
Table 2. Medium composition and growth of S. cerevisiae BBI on mannitol

Complete medium and growth conditions were as described in Methods. All results are means $\pm \mathrm{SE}$ of the two experiments.

$\quad$ Medium
Complete (yeast extract + peptone + salts)
Yeast extract + salts
Yeast extract + peptone
Yeast extract
Peptone + salts
Peptone
Complete (half strength)

Growth
(mg dry wt ml-1)
$11 \cdot 13 \pm 0.19$
$8.17 \pm 0.12$
$1.29 \pm 0.10$
$0.68 \pm 0$
0
0
$0.48 \pm 0.08$

Our results are broadly consistent with those of Maxwell \& Spoerl (1971) who, working with a non-growing strain of $S$. cerevisiae, observed that transport of mannitol was poor with an apparent $K_{\mathrm{m}}$ of $0.6 \mathrm{M}(10.8 \%$, w/v). However, the results presented in Fig. 1 suggest that with strains grown on mannitol the kinetics of mannitol transport may vary widely. It would be expected that strains (e.g. BB6) exhibiting good growth on low (1\%) or high (5\%) mannitol concentrations would have a greater affinity for this substrate than strains (e.g. BB1) only capable of growth at mannitol concentrations of $5 \%$ or more.

\section{Influence of medium composition on growth}

Whereas YEP/mannitol medium was capable of supporting excellent growth of many strains of $S$. cerevisiae, the fully defined Difco yeast nitrogen base failed to support such growth. Glutamic acid, which is necessary for growth on ethanol in defined medium (Bonnet et al., 1980), was without effect. It was shown that for growth of strain BB1 on mannitol the medium must contain both yeast extract $(1 \%, \mathrm{w} / \mathrm{v})$ and salts, whereas bacteriological peptone was not required (Table 2). It is therefore apparent that medium composition can determine whether or not $S$. cerevisiae can utilize mannitol. Although we have not attempted to identify growth promoting factor(s), it is clear that the requirement is satisfied by inclusion in the medium of relatively large amounts of yeast extract and salts.

\section{Adaptation of non-growing strains to growth on mannitol}

At least two strains were capable of growth on mannitol after long-term adaption. Both NCYC 177 and BB5 could be induced to grow on mannitol either by repeated subculture on, or after lengthy (about $100 \mathrm{~h}$ ) lag phase in, YEP/mannitol medium. After adaptation, both strains could successfully be maintained on solid medium (YEP) containing mannitol (5\%). A degree of genetic heterozygosity (Spencer \& Spencer, 1983) was observed in that not all single colonies from such plates retained the long-term capacity for growth on mannitol. Maintenance of adapted strains on solid medium containing glucose alone, or a mixture of mannitol and glucose, resulted in the complete loss of adapted growth. Such adaptation to growth on mannitol is likely to be due to the induction of key degradative enzymes or transport permeases. However, the response is not universal with initially non-growing strains: only a minority are subject to adaptation.

\section{Enzymology}

In agreement with previous observations (Muller, 1937; Wolf \& Kaplan, 1956; Wilhelmsen, 1961), a NAD+-dependent D-mannitol dehydrogenase could be detected in cell-free preparations of $S$. cerevisiae. The enzyme from mannitol-grown strain BB1 exhibited normal Michaelis-Menten kinetics for D-mannitol with an apparent $K_{\mathrm{m}}$ of $5.1 \mathrm{mM}$. The specific activity of the enzyme was $128.8 \pm 0.8 \mathrm{nmol}$ mannitol oxidized $\mathrm{min}^{-1}$ (mg protein) $)^{-1}$. No activity was found when $\mathrm{NADP}^{+}$replaced $\mathrm{NAD}^{+}$or when mannitol was replaced by mannitol 1-phosphate, sorbitol or ribitol. In glucose-grown cells the activity of the enzyme was about $10 \%$ of that found in mannitol-grown cells. 


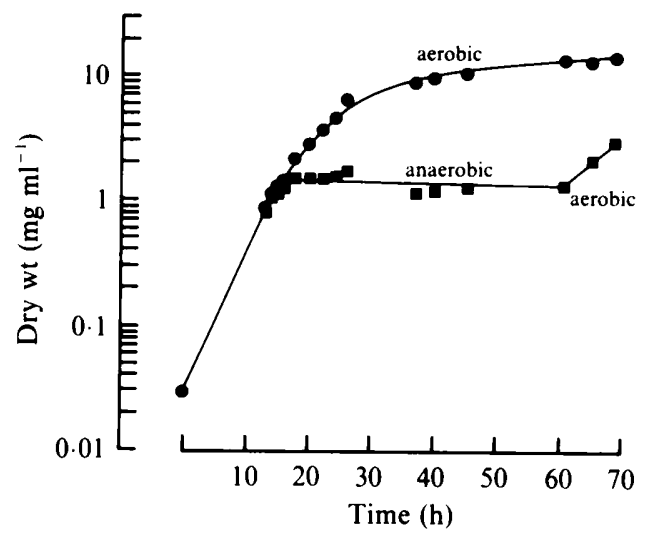

Fig. 2. Effects of anaerobiosis on the growth of $S$. cerevisiae BB1 on mannitol $(5 \%, \mathrm{w} / \mathrm{v})$. Experimental design was as described in Methods.
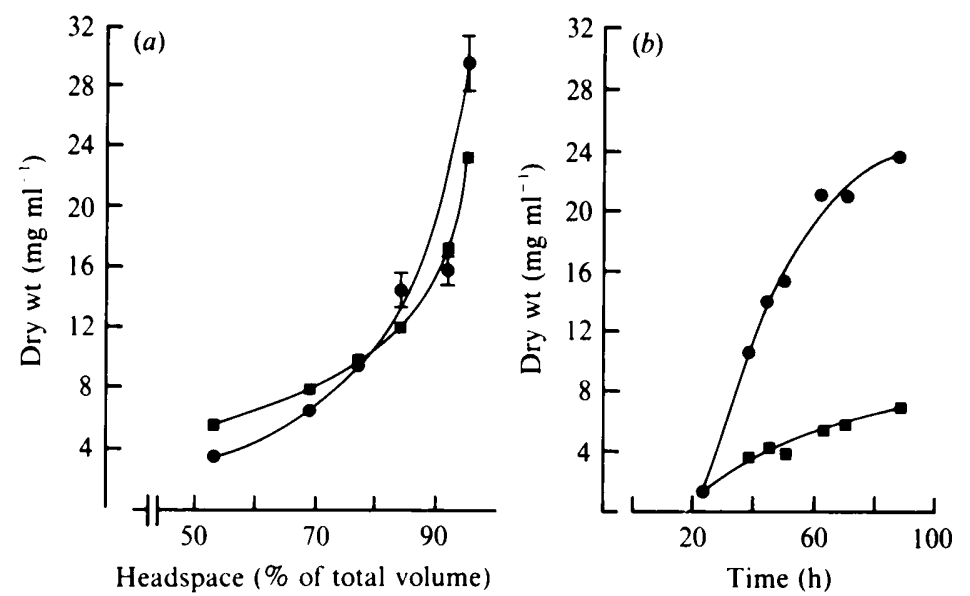

Fig. 3. Oxygen transfer rate and the growth of $S$. cerevisiae on mannitol $(10 \%, w / v)$. (a) Effect of culture volume on growth yield for BB1 ( $\square$ ) and NCYC $430(O)$. (b) Growth of NCYC 430 under conditions of high $(\bigcirc)$ and low $(\square)$ aeration. For experimental details see Methods. Results are the mean $( \pm S E)$ of two separate experiments.

\section{Requirement for oxygen}

Maxwell \& Spoerl (1971) demonstrated that transport of mannitol into S. cerevisiae was markedly reduced in the absence of both a fermentable carbon source and oxygen. Our preliminary observations (Walton et al., 1984), showed that oxygen was necessary for growth of yeast on mannitol. In stirred fermenters where the headspace gas was changed from air to nitrogen, exponential growth of strain BBl promptly ceased (Fig. 2). The transition back from anaerobiosis to aerobiosis resulted in exponential growth recommencing.

The importance of oxygen in determining the growth yield of $S$. cerevisiae on mannitol was also demonstrated by manipulation of the rate of oxygen transfer by adjusting the culture volume (Freedman, 1969). Growth of both BB1 and NCYC 430 on mannitol was greatest under conditions of high oxygen transfer (small culture volume, large headspace) (Fig. $3 a$ ). As culture volume increased, concomitant with decreasing rate of oxygen transfer, biomass yields declined dramatically. Similarly, in a different experiment with strain BB1, markedly different rates of growth were found under conditions of high and low aeration (Fig. $3 b$ ).

Measurement of sterols, whose synthesis is determined by the availability of oxygen (for a review see Parks, 1978), confirmed that higher rates of aeration supported additional sterol 
Table 3. Respiration of ethanol by $S$. cerevisiae BBl after growth on different carbon sources

Cells were grown in complete media as described in Methods and harvested after 16 or $48 \mathrm{~h}$. With the exception of ethanol $(1 \%, v / v)$, all carbon sources were initially present at $5 \%(w / v)$. Results are means $\pm \mathrm{SE}$ for two experiments.

$\begin{array}{lcc}\text { Carbon source } & \begin{array}{c}\text { Growth } \\ \left(\mathrm{mg} \text { dry wt } \mathrm{ml}^{-1}\right)\end{array} & \begin{array}{c}\text { Respiration } \\ \text { [nmol } \mathrm{O}_{2}(\mathrm{mg} \text { dry wt) }\end{array} \mathrm{min}^{-1} \text { ] }\end{array}$

synthesis. In an experiment with NCYC 177, under conditions of high aeration total sterol concentration was $173.0 \pm 10.9 \mu \mathrm{g} \mathrm{ml}^{-1}$ or $1.47 \pm 0.09 \%$ of the dry biomass. Under conditions of low aeration, these values were respectively $62.5 \pm 0.2 \mu \mathrm{g} \mathrm{ml}^{-1}$ and $1.00 \pm 0 \%$ (mean $\pm \mathrm{SE}$ ).

\section{Requirement for mitochondrial function}

Previous observations (Walton et al., 1984) showed that treatment of strain BB1 with erythromycin (an inhibitor of mitochondrial protein synthesis) or the isolation of respiratory deficient mutants, resulted in the inability to grow on mannitol. Such observations, coupled with the requirement for oxygen, suggest that mannitol metabolism in $S$. cerevisiae requires mitochondrial function.

In S. cerevisiae, substrates requiring mitochondrial function for their catabolism are described as supporting catabolite derepression (for reviews see Linnane \& Haslam, 1970; Fiechter et al., 1981). Measurement of rates of respiration of ethanol (Table 3) by strain BB1 after growth on a range of carbon sources showed that mannitol-grown cells exhibited similar respiratory activity to that of cells grown on ethanol, a substrate supporting full catabolite derepression. Respiration could not be detected in yeast grown on fermentable, catabolite-repressing substrates such as glucose and fructose. Although mannitol-grown cells supported similar rates of respiration with both glucose and ethanol, mannitol $(25 \mathrm{mM})$ was a poor substrate, supporting only $6-10 \%$ of the maximal rate. This further suggests that in some strains of $S$. cerevisiae transport of mannitol may limit its rate of catabolism.

\section{Growth rate and products of mannitol metabolism in batch culture}

Further insight into the mode of mannitol metabolism was obtained by monitoring substrate utilization and product formation during batch culture. Similar experiments were done with glucose and with galactose, which supports intermediate levels of respiratory activity and catabolite repression (Strittmatter, 1957; De Deken, 1966; Lagunas, 1976; Baldacci \& Zennaro, 1982; Busturia \& Lagunas, 1986) (Fig. 4).

The specific growth rate of strain BB1 on $5 \%$ mannitol $\left(0.144 \mathrm{~h}^{-1}\right)$ was markedly less than that on galactose $\left(0.289 \mathrm{~h}^{-1}\right)$ or glucose $\left(0.333 \mathrm{~h}^{-1}\right)$, rates which were both in close agreement with previous observations (Lagunas, 1976). However, the specific growth rate of this strain on mannitol was still faster than for growth on ethanol (Lagunas, 1976; Quain \& Haslam, 1979). Although, as expected, the rates of substrate uptake reflected the rate of growth (Fig. 4), mannitol uptake was extremely slow, although markedly more biomass production was supported than for the other substrates. Measurement of the yield coefficient (Bauchop \& Elsden, 1960) showed that $50.1 \mathrm{~g}$ dry wt of yeast was formed per mol mannitol consumed.

Measurement of products of metabolism confirmed that mannitol, like galactose, is metabolized extensively, although not exclusively, via oxidation. Fig. 4 shows growth by fermentation of glucose (about $\left.50 \mathrm{gl}^{-1}\right)$ yielded large amounts of ethanol $\left(26 \mathrm{gl}^{-1}\right)$ whereas 


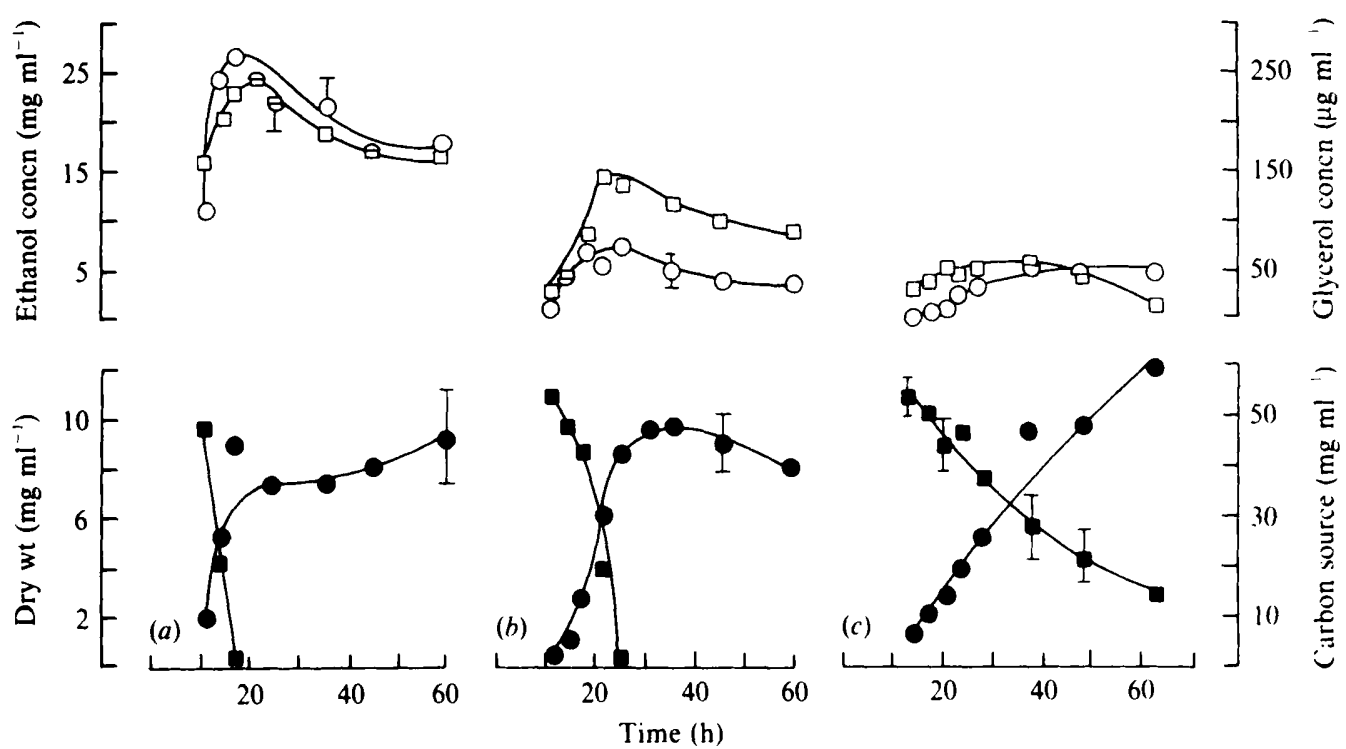

Fig. 4. Growth and products of metabolism during batch culture of $S$. cerevisiae BBI on complex medium containing $5 \%(w / v)$ glucose $(a)$, galactose $(b)$ and mannitol $(c)$. , Substrate; , yeast dry wt; $O$, concentration of ethanol; $\square$, concentration of glycerol. Error bars indicate the mean of duplicate measurements.

growth on galactose or mannitol resulted in maximum levels of 7 and $5 \mathrm{~g}$ ethanol $1^{-1}$ respectively. Growth on glucose was diauxic, such that with the exhaustion of glucose, catabolite derepression occurred. This new phase of growth was characterized by the assimilation and oxidation of ethanol, the product of the first phase of growth. The levels of glycerol, although two orders of magnitude lower than those of ethanol, are a reflection of the need to regenerate $\mathrm{NAD}^{+}$from NADH so as to maintain glycolysis (Oura, 1977). The magnitude of glycerol synthesis may also indicate the extent of respiratory activity which occurs during growth (Lagunas, 1976; Oura, 1977). the relatively small amount of glycerol produced during growth on mannitol was consistent with growth on this substrate being largely via aerobic respiration.

\section{Mannitol metabolism in the absence of a nitrogen source}

Mannitol-grown NCYC 430 was subjected to nitrogen starvation in the presence of either glucose or mannitol. In agreement with the results of others (Rothman \& Cabib, 1969; Lillie \& Pringle, 1980), nitrogen limitation in the presence of glucose resulted in biomass accumulation $\left(2.28-3.89 \mathrm{mg}\right.$ dry $\left.\mathrm{wt} \mathrm{ml}^{-1}\right)$ and in the synthesis of the reserve polysaccharide glycogen, which increased from 122 to $202 \mu \mathrm{g} \mathrm{ml}^{-1}$. However, under conditions of nitrogen starvation, mannitol was unable to support new biomass production and glycogen levels declined from 122 to $83 \mu \mathrm{g} \mathrm{ml}^{-1}$. Presumably nitrogen starvation in the presence of this oxidizable carbon source cannot support energy generation and biomass accumulation, unlike the case for fermentable carbon sources.

\section{Redox balance and mannitol metabolism}

The most plausible explanation for the inability of mannitol to support fermentative growth of $S$. cerevisiae is that this would result in the deregulation of the redox balance (for a review see van Dijken \& Scheffers, 1986). As the products of the reaction catalysed by $\mathrm{NAD}^{+}$-dependent mannitol dehydrogenase are fructose and $\mathrm{NADH}$, the overall equation for the anaerobic conversion of mannitol to ethanol would be: 


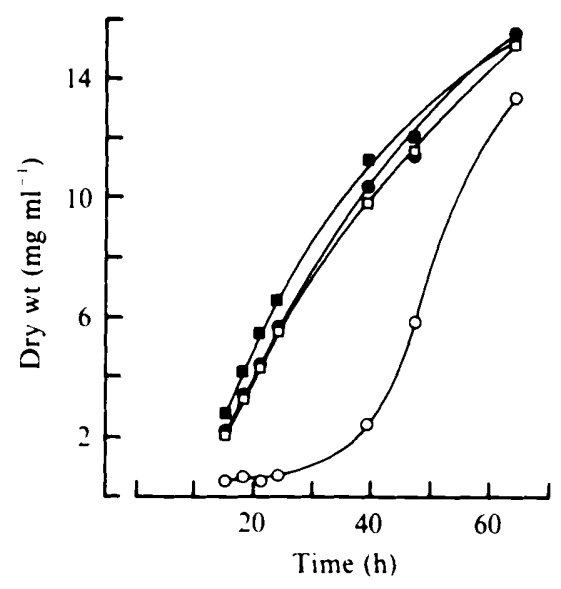

Fig. 5. Growth of NCYC $430(0, O)$ and NCYC $1415(\square, \square)$ on $5 \%(w / v)$ mannitol $(O, \square)$ and sorbitol $(O, \square)$. Results are the mean of two experiments; the variation of each point was less than $5 \%$.

Hence, although potentially energy yielding, anaerobic fermentation of mannitol would result in the production of excess NADH. Since transhydrogenation does not occur in yeasts (van Dijken \& Scheffers, 1986) and because mitochondrial function cannot occur in anaerobic $S$. cerevisiae, excess NADH is oxidized in the formation of the energetically expensive glycerol (Oura, 1977). However, as is shown in equation (2) maintenance of the redox balance through the synthesis of glycerol would result in no overall ATP production.

$$
\begin{gathered}
2 \text { Mannitol }+4 \mathrm{NAD}^{+}+4 \mathrm{NADH}+4 \mathrm{ATP}+4 \mathrm{ADP} \rightarrow 2 \text { Ethanol }+2 \mathrm{CO}_{2}+ \\
2 \text { Glycerol }+4 \mathrm{NADH}+4 \mathrm{NAD}^{+}+4 \mathrm{ATP}+4 \mathrm{ADP}
\end{gathered}
$$

Hence, it may be concluded that growth of $S$. cerevisiae on mannitol is irretrievably dependent on oxidative metabolism. Bruinenberg et al. (1983) have proposed a similar interpretation to explain the absence of anaerobic fermentation of xylose by Candida utilis. In this case the conversion of xylitol to xylulose by xylitol dehydrogenase results in the net production of NADH.

\section{Screening of strains of $S$. cerevisiae for growth on sorbitol}

Of the 40 strains of $S$. cerevisiae screened for growth on mannitol (Table 1), only 4 (NCYC 430 , $679,933$ and 1415$)$ were capable of aerobic growth on sorbitol (5\%). Each of these strains also grew well on mannitol. Contrary to the findings of Tyson et al. (1979), we were unable to demonstrate growth of strain S288C (or the other haploids) on sorbitol. NCYC 1415 grew equally well on either polyol whereas NCYC 430 exhibited a lengthy lag phase before growth on sorbitol (Fig. 5). As with strains showing adaptation to growth on mannitol, sorbitol-grown NCYC 430 could retain this capability by maintenance on solid medium containing sorbitol $(5 \%)$. Our observations suggest no common polyol transport/dehydrogenase system for mannitol and sorbitol. Many more strains were able to grow on mannitol than sorbitol and transfer of mannitol-grown cells to fresh medium containing sorbitol did not result in growth.

We acknowledge the technical contributions of Marie Brannan, Andrew Jones, Rory Bolton and especially, Angela Willshaw. We thank Dr Fintan Walton for early work on the genetics of mannitol utilization and enthusiastic discussion, and Dr Charles Bamforth for support and critical reading of the manuscript. We are grateful to the Directors of Bass PLC for permission to publish this paper. 


\section{REFERENCES}

Astin, A. M., Haslam, J. M. \& Woods, R. A. (1977). The manipulation of cellular cytochrome and lipid composition in a haem mutant of Saccharomyces cerevisiae. Biochemical Journal 166, 275-285.

BaldaCCI, G. \& ZenNaro, E. (1982). Mitochondrial transcripts in glucose-repressed cells of Saccharomyces cerevisiae. European Journal of Biochemistry 127, 411-416.

BARNeTt, J. A. (1968). The catabolism of acyclic polyols by yeasts. Journal of General Microbiology 52 , 131-159.

Barnett, J. A., Payne, R. W. \& Yarrow, D. (1983). Yeasts: Characteristics and Identification. Cambridge: Cambridge University Press.

BAUCHOP, T. \& ElSDEN, S. R. (1960). The growth of micro-organisms in relation to their energy supply. Journal of General Microbiology 23, 457-469.

Bisson, L. F. \& FraENKEL, D. G. (1983). Involvement of kinases in glucose and fructose uptake by Saccharomyces cerevisiae. Proceedings of the National Academy of Sciences of the United States of America 80, $1730-1734$.

BoEHringer MANNHEIM (1980). Methods of Enzymatic Food Analysis. Mannheim: Boehringer Mannheim $\mathrm{GmbH}$.

BONNET, J. A. B. A. F., DE KoK, H. E. \& RoEls, J. A. (1980). The growth of Saccharomyces cerevisiae CBS426 on mixtures of glucose and ethanol: a model. Antonie van Leeuwenhoek 46, 565-576.

Bruinenberg, P. M., DE Bot, P. H. M., van DiJken, J. P. \& SCHEFfers, W. A. (1983). The role of redox balances in the anaerobic fermentation of xylose by yeasts. European Journal of Applied Microbiology and Biotechnology 18, 287-292.

Busturia, A. \& Lagunas, R. (1986). Catabolite inactivation of the glucose transport system in Saccharomyces cerevisiae. Journal of General Microbiology 132, 379-385.

CaNh, D. S., Horak, J., Kotyk, A. \& Rihova, L. (1975). Transport of acyclic polyols in Saccharomyces cerevisiae. Folia microbiologica 20, 320-325.

COOPER, T. G. (1982). Transport in Saccharomyces cerevisiae. In The Molecular Biology of the Yeast Saccharomyces. Metabolism and Gene Expression, pp. 399-461. Edited by J. N. Strathern, E. W. Jones \& J. R. Broach. Cold Spring Harbor, NY: Cold Spring Harbor Laboratory.

DE DeKen, R. H. (1966). The Crabtree effect: a regulatory system in yeast. Journal of General Microbiology 44, 149-156.

van DiJken, J. P. \& Scheffers, W. A. (1986). Redox balances in the metabolism of sugars by yeasts. FEMS Microbiology Reviews 32, 199-224.

Fiechter, A., FuhrmanN, G. F. \& KaPPELI, O. (1981). Regulation of glucose metabolism in growing yeast cells. Advances in Microbial Physiology 22, 123183.

FrAENKEL, D. G. (1982). Carbohydrate metabolism. In The Molecular Biology of the Yeast Saccharomyces. Metabolism and Gene Expression, pp. 1-37. Edited by J. N. Strathern, E. W. Jones \& J. R. Broach. Cold Spring Harbor, NY: Cold Spring Harbor Laboratory.

Freedman, D. (1969). The shaker in bioengineering. Process Biochemistry March, 35-40.
Gonzales, R. A. \& Parks, L. W. (1977). Acidlabilisation of sterols for extraction from yeast. Biochimica et biophysica acta 489, 507-509.

Heredia, C. F., Sols, A. \& Delafuente, G. (1968). Specificity of the constitutive hexose transport in yeast. European Journal of Biochemistry 5, 321329.

KIRSOP, B. (1974). Segregation of strains of brewing yeast by their carbon assimilation patterns. Journal of the Institute of Brewing 80, 555-557,

LAGUNAS, R. (1976). Energy metabolism of Saccharomyces cerevisiae: discrepancy between ATP balance and known metabolic functions. Biochimica et biophysica acta 440, 661-674.

Lewis, D. H. \& Harley, J. L. (1965). Carbohydrate physiology of mycorrhizal roots of beech. 1. The identity of endogenous sugars and the utilisation of exogenous sugars. New Phytologist 64, 224-237.

Lillie, S. H. \& Pringle, J. R. (1980). Reserve carbohydrate metabolism in Saccharomyces cerevisiae: responses to nutrient limitation. Journal of Bacteriology 143, 1384-1394.

Linnane, A. W. \& Haslam, J. M. (1970). The biogenesis of mitochondria in Saccharomyces cerevisiae. Current Topics in Cellular Regulation 2, 101172.

LinNane, A. W. \& Lukins, H. B. (1975). Isolation of mitochondria and techniques for studying mitochondrial biogenesis in yeasts. Methods in Cell Biology 12 , 285-309.

MaXwell, W. A. \& Spoerl, E. (1971). Mannitol uptake by Saccharomyces cerevisiae. Journal of Bacteriology 105, 753-758.

MULLER, D. (1937). Mannite dehydrase. Enzymologia 3, 26-28.

OURA, E. (1977). Reaction products of yeast fermentation. Process Biochemistry April, 19-21.

PARKS, L. W. (1978). Metabolism of sterols in yeast. CRC Critical Reviews in Microbiology 6, 301-341.

QUAIN, D. E. (1981). The determination of glycogen in yeasts. Journal of the Institute of Brewing 87, 289-291.

QUAIN, D. E. (1986). Differentiation of brewing yeasts. Journal of the Institute of Brewing 92, 435-438.

QuaIN, D. E. \& Boulton, C. A. (1986). The utilisation of mannitol by Saccharomyces cerevisiae. In $A b$ stracts, XIV International Congress of Microbiology, Manchester, p. 247, abstract pG4-18.

Quain, D. E. \& Haslam, J. M. (1979). The effects of catabolite repression on the accumulation of steryl esters and the activity of $\beta$-hydroxy- $\beta$-methylglutaryl-CoA reductase in Saccharomyces cerevisiae. Journal of General Microbiology 111, 343-351.

Rothman, L. B. \& CABIB, E. (1969). Regulation of glycogen synthesis in the intact yeast cell. Biochemistry 8, 3332-3341.

Spencer, J. F. T. \& Spencer, D. M. (1983). Genetic improvement of industrial yeasts. Annual Review of Microbiology 37, 121-142.

SPOERL, E. \& DOYLE, R. J. (1968). Selective enhancement of glycolytic activity by incubation of yeast cells in sugars and polyols. Canadian Journal of Microbiology 14, 1245-1252.

StrittMatTER, C. F. (1957). Adaptive variation in the level of oxidative activity in Saccharomyces cerevisiae. Journal of General Microbiology 16, 169-183. 
Tyson, C. B., LoRd, P. G. \& Wheals, A. E. (1979). Dependency of size of Saccharomyces cerevisiae cells on growth rate. Journal of Bacteriology 138, 92-98.

Wallace, P. G., Huang, M. \& Linnane, A. W. (1968). Influence of medium composition on the cytology of anaerobically grown Saccharomyces cerevisiae. Journal of Cell Biology 37, 207-220.

VAN DER WALT, J. P. (1970). Saccharomyces cerevisiae: Hansen. In The Yeasts. A Taxonomic Study, 2nd edn, pp. 595-604. Edited by J. Lodder. Amsterdam \& London: North Holland Publishing Company.

Walton, E. F., Quain, D. E. \& Brannan, M. (1984). The genetics and physiology of mannitol utilisation in Saccharomyce cerevisiae. In Proceedings of the $12 \mathrm{th}$ International Conference on Yeast Genetics and Molecular Biology, Edinburgh pp. 27, Abstract A.12.
WILES, A. E. (1953). Identification and significance of yeasts encountered in the brewery. Journal of the Institute of Brewing 59, 265-284.

Wilhelmsen, J. B. (1961). Polyol dehydrogenase in yeast. Enzymologia 23, 259-266.

WOlFF, J. B. \& KaPlaN, N. O. (1956). Hexitol metabolism in Escherichia coli. Journal of Bacteriology 71, 557-564.

WoOds, R. A., BARD, M., Gardner, I. E. \& MolzahN, S. W. (1974). Studies on the accumulation of ergosterol and 24(28)-dehydroergosterol in 3 strains of Saccharomyces cerevisiae. Microbios 10A, 73-80.

ZIFFER, J. (1983). Hexitol repression effects in the high corn ethanol fermentation system. Biotechnology Letters 5, 805-810. 